\title{
CUTTING THE COMMON REED STALK WHILE MAINTAINING ITS CROSS-SECTIONAL SHAPE
}

\author{
Imants Nulle, Aivars Kakitis, Olafs Vronskis, Mareks Smits \\ Latvia University of Life Sciences and Technologies, Latvia \\ imants.nulle@1lu.lv, aivars.kakitis@1lu.lv,olafs.vronskis@1lu.lv, mareks.smits@1lu.lv
}

\begin{abstract}
Common reed (Phragmites australis) is a grass which has spread nearly all over the globe. It is common in many kinds of wet habitats. Common reed is a very tall grass, reaching at best the height of four meters on the coasts of the Baltic Sea. In the wintertime the straw becomes a hard, yellowish stem, which makes it possible to exploit the reed also in construction. Reed beds proliferated quickly in our coastal areas in the late 20 th century after pasturage came to its end, due to the nutrient load from air and water, as well as the mild winters. Reed material has been exploited in many ways around the Baltic Sea. For building purposes, reed can be gathered in winter and early spring from the top of ice or other hard surfaces. Reed has been exploited for centuries. It has been used for feeding animals, in bed clothing and in construction. In construction, reed has been used for roof materials and heat insulation. Common reeds with their properties can be used not only for the purposes mentioned above. People are increasingly focusing on sustainable development and the use of natural materials instead of plastics. The reed stem is like a natural pipe. It is already used in the production of cocktail straws. However, there is a much wider range of uses, such as toy components etc. Such applications require that the reed stem is not flattened after cutting. Likewise, the end of the stem must be free of sharp edges and smooth. This article investigates reed cutting using abrasive discs. Cutting speed is important for good quality of cuts. Therefore, different cutting speeds in the experiments are used. The quality of the slice was evaluated using a digital microscope. Cutting power is calculated from the torque and rotation speed.
\end{abstract}

Keywords: common reed, cutting, abrasive discs.

\section{Introduction}

Lakes constitute about $1000 \mathrm{~km}^{2}$ or $1.5 \%$ of the national territory of Latvia. The number of lakes larger than 1 ha is 2256, 16 lakes are greater than $10 \mathrm{~km}^{2}$ and add up to $45 \%$ of the total area of lakes in Latvia. Latvia's lakes are characterized by eutrophication, which often has a negative impact on lake biotopes, as rotting water plant remnants are emitting methane $\left(\mathrm{CH}_{4}\right)$ in the atmosphere. Cutting and harvesting the reed can decelerate eutrophication processes [1].

Expanding reed beds pose a challenge to both coastal residence and natural biodiversity. When overgrowing recreational areas along the coastal areas, reeds trouble surface water quality, boating and swimming, and thus bring forth the need to get rid of reed where it is concerned as a nuisance [2].

Reed beds ensure also biological self-cleaning of nature, because the submerged reed roots consume nutrients directly from water. Too intensive use of reed beds or continuous reduction of reed bed areas may result in the loss of the habitats of certain species and decrease the self-cleaning ability of water bodies. At the same time there are also such species whose habitats are threatened by reed overgrowth. In addition, it should be taken into account that reed is also a valuable renewable resource and it is an excellent building material in many ways. Therefore, finding balance between the protection of reed beds and other nature values is ultimately important [2;3].

Removing plant biomass from reservoirs is an effective method of their phytoremediation, albeit problematic for technological and economic reasons. Therefore, a very important aspect of removing emerging vegetation from lakes is the possibility of managing it in such a way as to achieve financial benefits [4].

Reeds can be used as an environmentally friendly alternative to firewood, but its efficient use should take into account the following factors: biomass with low humidity obtainable late in winter, the combustion process has a high ash level and before transporting it should receive primary treatment to increase the bulk density and reduce the transport costs. Reed as a separate fuel material is effective for solid fuel boilers, located close to the resource extraction site. An optimal use of this biomass source is possible in combination with other energy sources to produce pellets or briquettes [5].

People are increasingly focusing on sustainable development and the use of natural materials instead of plastics. However, reeds have many other uses, they can be used as decorative elements in 
everyday interiors, they can be used for carpets, wall coverings, cocktail straws, Christmas decorations and kids' toys (Fig. 1).

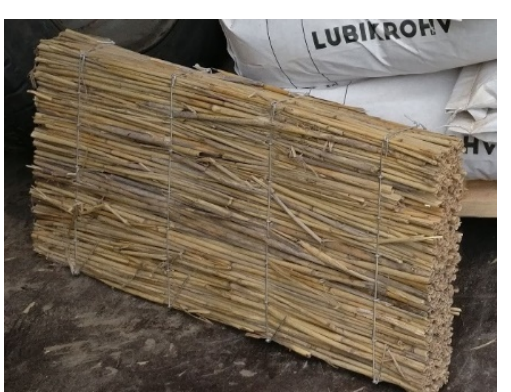

Panels

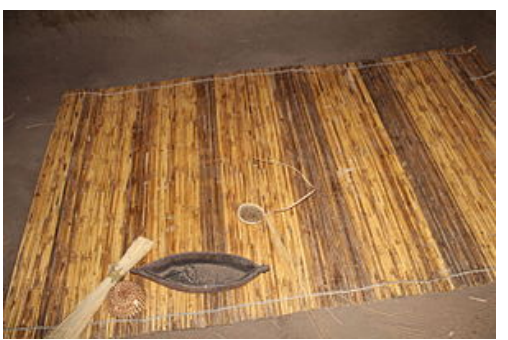

Carpets

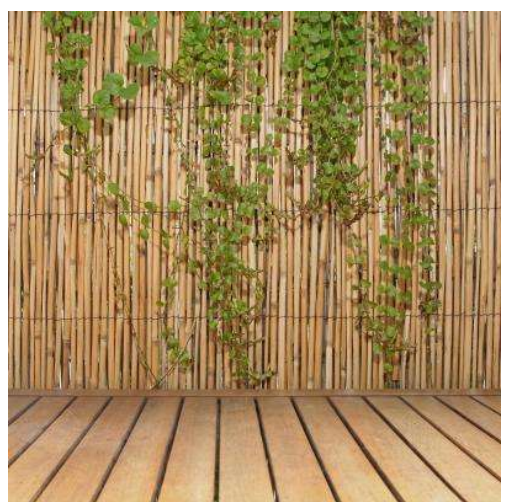

Windbreak

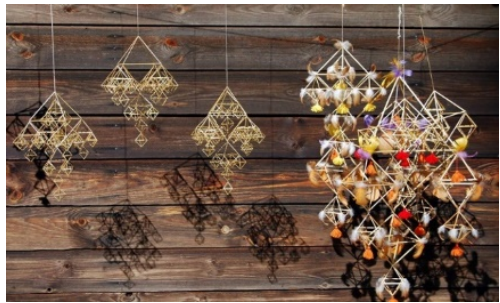

Christmas decorations

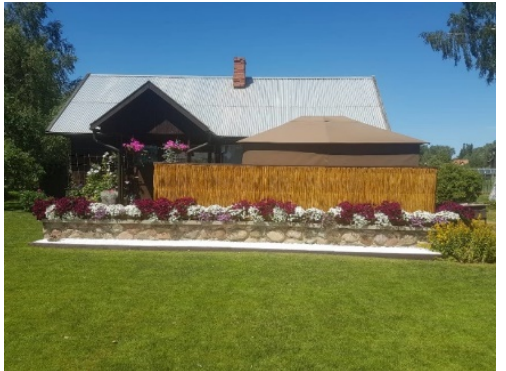

Screen Walls

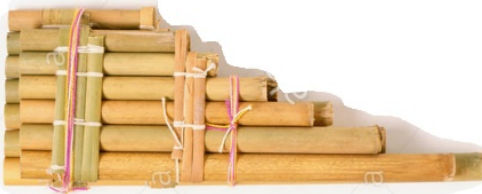

Reed pipe

Fig. 1. Examples of common reed application

Some of these applications require that the reed stem is not flattened after cutting, as in processes where reeds are used as a building material they are cut with different types of knives (Fig. 2 and Fig. 3). Likewise, the end of the stem must be free of sharp edges and smooth.

Abrasive cutting is considered as one of the possible methods of reed straw cutting. The study will determine what feed rate is suitable for obtaining a quality result and how the required energy changes depending on the feed rate.
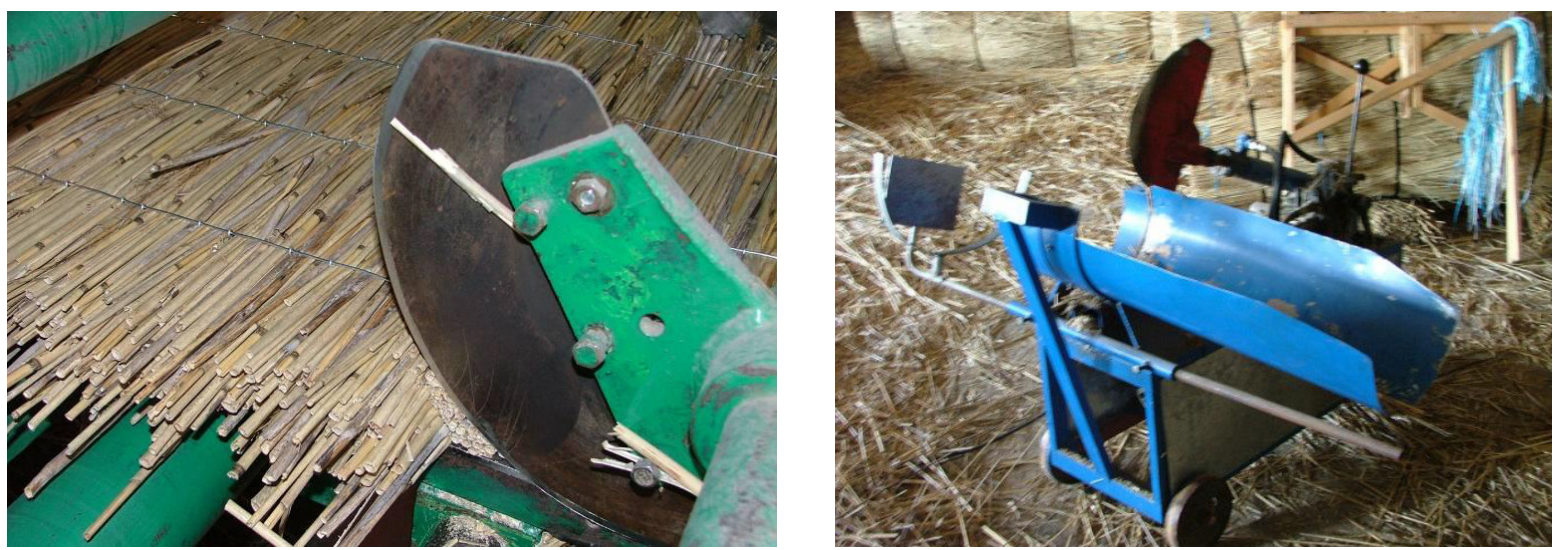

Fig. 2. Cutting of the ends of the reed board [2] Fig. 3. Cutting of the ends of the reed bundles [2]

\section{Materials and methods}

A stand with adjustable rotation speed was used to determine the cutting feed speed(Fig. 4).The stand includes a frequency converter (2), motor reducer (5), torque transmitter (6), shaft (7) with brackets (8) for fixing reeds.For torque and angle registration in a dynamic regime the measuring equipment MOUNTZ (4) with a smart torque sensor was used (Fig. 4). 
For measurement data registration the MOUNTZ torque gauge Torque mate PTT was used. The system provides an accuracy $\pm 0.5 \%$ of full scale. The meter is equipped with a computer program that provides signal filtering and obtained calibration data registration in the computer. To measure the torque the smart sensor RTSX50i-A was used with a range of $565 \mathrm{cNm}$. The sensor non-linearity is $\pm 0.2 \%$. Interchangeability error does not exceed $\pm 0.3 \%$. Gauge bridge resistance is $350 \Omega$.

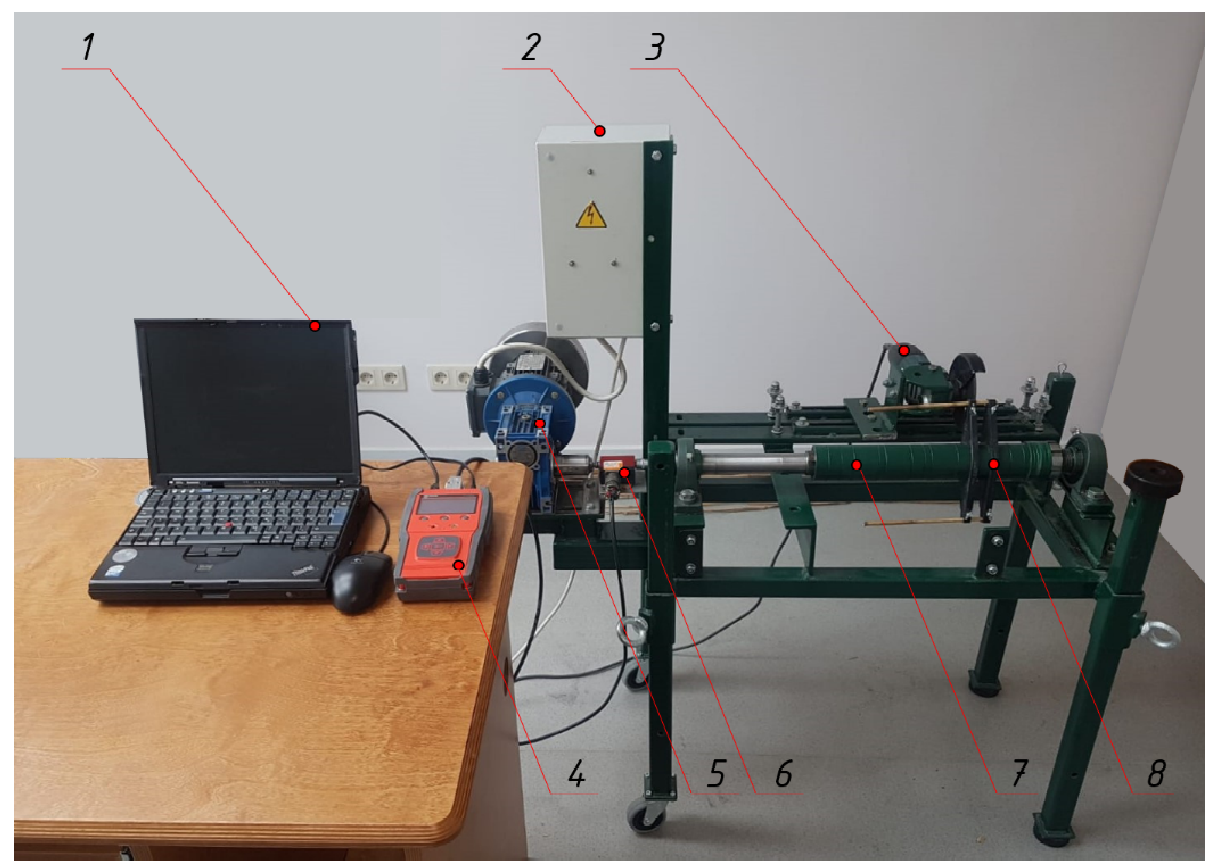

Fig. 4. Experimental equipment

The calculation of the feed energy for one cut $E_{1 i}$ is done according to equation (1):

$$
E_{1 i}=\left[\left(\frac{T_{1}+T_{2}}{2}\right) \Delta t+\left(\frac{T_{2}+T_{3}}{2}\right) \Delta t+\ldots+\left(\frac{T_{n}+T_{n+1}}{2}\right) \Delta t\right] \cdot \omega,
$$

where $E_{1 i}-$ cutting energy for one cut, $\mathrm{J}$;

$T_{1}$ - first data point (torque), $\mathrm{Nm}$;

$T_{2}$ - second data point (torque), $\mathrm{Nm}$;

$T_{n}-\mathrm{n}^{\text {th }}$ data point (torque), $\mathrm{Nm}$;

$\Delta t$ - time interval between data points, $\mathrm{s}$;

$\omega-$ angular velocity, $\mathrm{s}^{-1}$.

Grinding wheel diameter $125 \mathrm{~mm}$ and thickness $1 \mathrm{~mm}$. Rotation frequency $10000 \mathrm{~min}^{-1}$. The diameter of the reeds used in the experiments is $7.2 \pm 0.12 \mathrm{~mm}$. Reed wall thickness $0.83 \mathrm{~mm}$.

\section{Results and discussion}

The obtained torque was converted to the feed force during cutting. This will be needed in the next stage of the study to calculate the cutting energy.

During the cutting process, it is possible to distinguish the moment when the grinding wheel touches the reed stalk, a peak formed in the graph (Fig. 5). When the stem wall is cut to the void inside the stem, the feed force decreases. This can be explained by changes in the cross-section of the material to be cut, the grinding wheel has to cut a smaller area. Exceeding the central part of the stem, the force increases again as the cutting area increases.

During the experiment, the shaft frequency was increased from 0.07 to $2.5 \mathrm{rad} \mathrm{s}^{-1}$, increasing the feed rate from 6 to $240 \mathrm{~mm} \mathrm{~s}^{-1}$. The results show that the maximum feed force value increases from 1 to $19 \mathrm{~N}$ (Fig. 19).Increased force at high speeds can destroy the round shape of the stalk. 


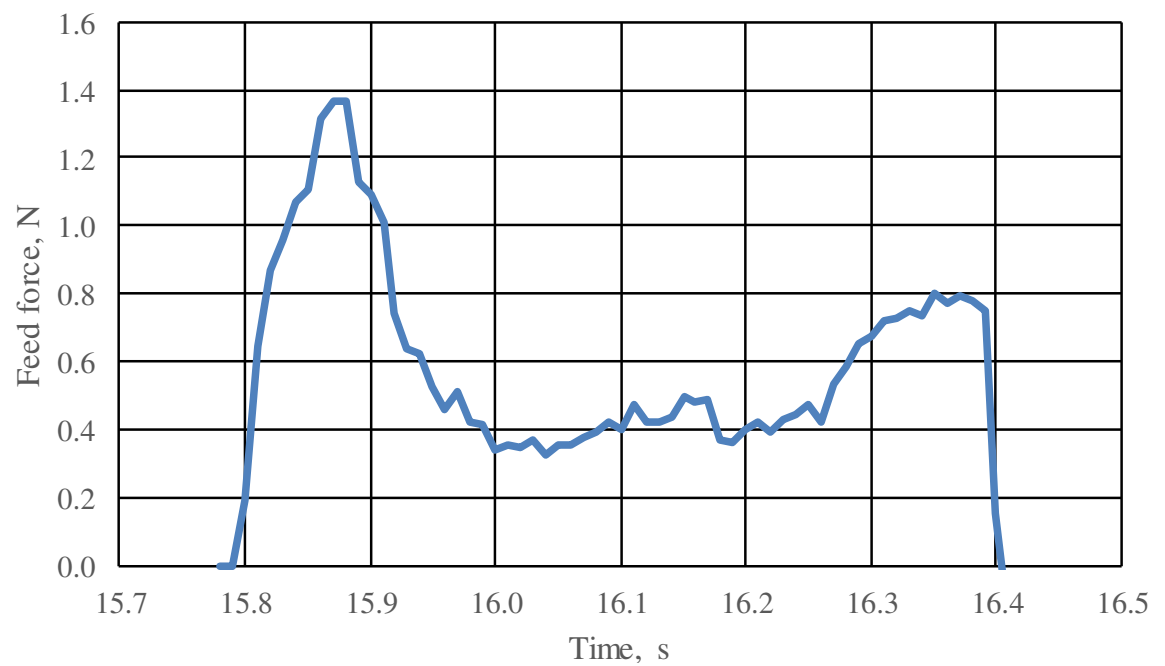

Fig. 5. Feed force at velocity $17 \mathrm{~mm} \cdot \mathrm{s}^{-1}$

At high feed rates, the energy required to move the stem in the direction of the grinding wheel also increases (Fig. 7). The energy consumed per one cut increases from $3.5 \pm 2$ to $130 \pm 35 \mathrm{~mW} \cdot \mathrm{s}$, increasing the feed rate from 6 to $240 \mathrm{~mm} \cdot \mathrm{s}^{-1}$. This is due to the inefficient operation of the abrasive disc at such high feed rates. It is not able to remove enough particles from the cut area for the cut to be of good quality. This is also evidenced by the analysis of the section images discussed below.

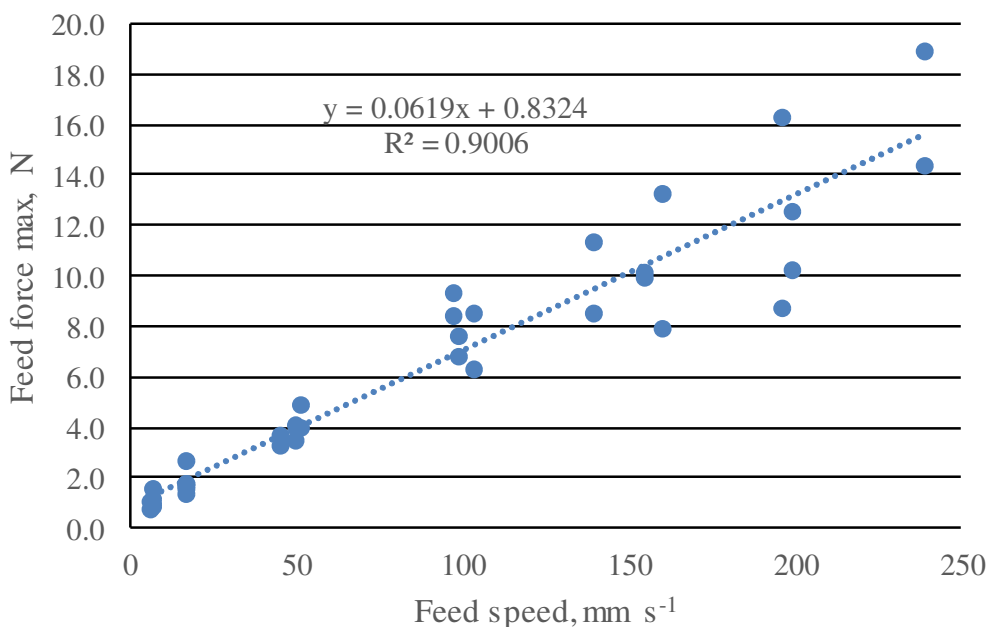

Fig. 6. Feed force vs. velocity

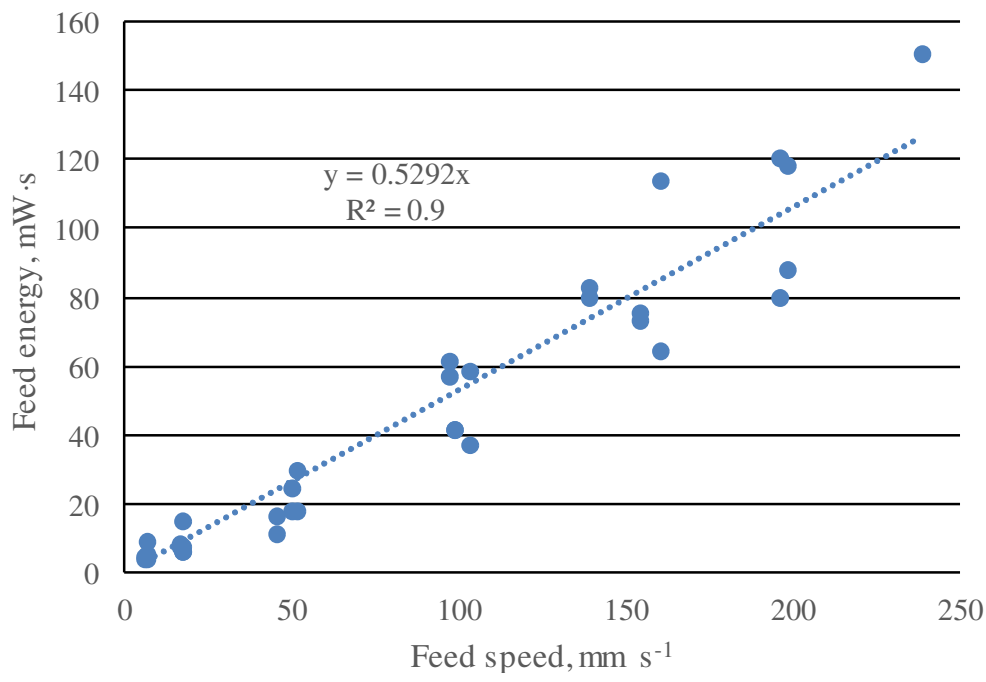

Fig. 7. Feed energy vs. velocity 
The feed rate also had a significant effect on the quality of the cut. At a speed of $6 \mathrm{~mm} \cdot \mathrm{s}^{-1}$ the cut is smooth and the torn particles are shorter than $1 \mathrm{~mm}$ (Fig. 8 a). The length of the torn particles exceeds $10 \mathrm{~mm}$ at a feed rate of $240 \mathrm{~mm} \cdot \mathrm{s}^{-1}$ (Fig. $8 \mathrm{~b}$ ). The cut is no anymore of high quality and such a product cannot be used for cocktail straws or other things that have a decorative meaning.

a)

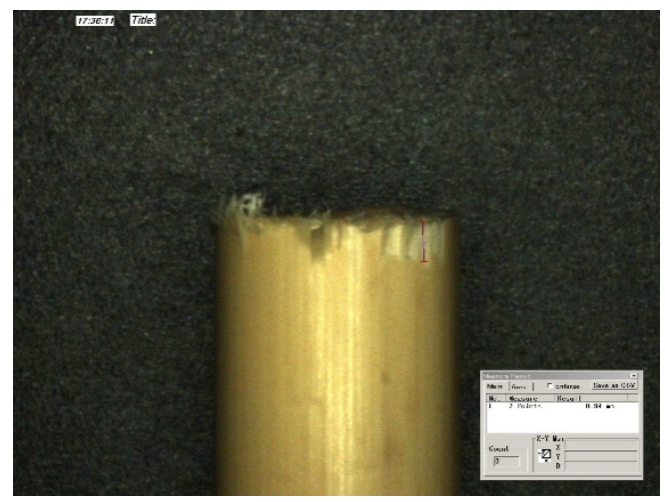

b)

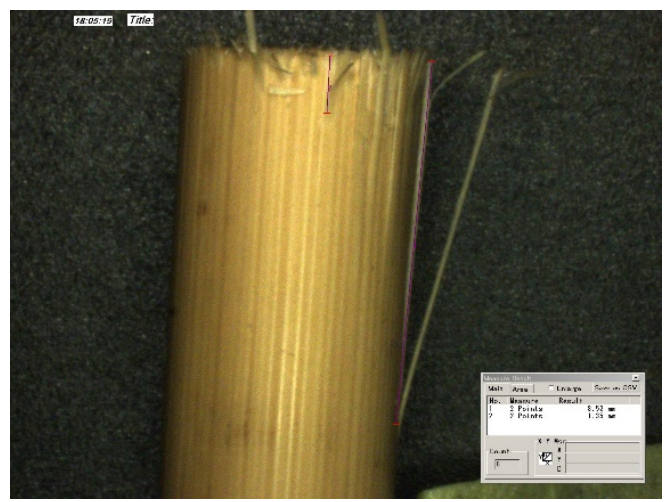

Fig. 8. Cut quality

\section{Conclusions}

1. For cutting reeds with a grinding wheel, a feed speed of no more than $10 \mathrm{~mm} \cdot \mathrm{s}^{-1}$ is recommended to keep the cut smooth.

2. A speed of $10 \mathrm{~mm} \cdot \mathrm{s}^{-1}$ will also provide a small feed force (around $1 \mathrm{~N}$ ), as the speed increases, the force generated by the grinding wheel colliding with the stem increases and can break the round shape of the stem.

3. The low feed rate also provides less energy required to feed the straw to the grinding wheel. And it is predicted that the grinding energy will be lower when the grinder works more efficiently at lower feed rates.

\section{References}

[1] Čubars E., Noviks G. Evaluation of reed resources in Kurzeme region in Latvia. Proceedings of the international scientific conference "Renewable energy and energy efficiency", May 28-30, 2012, Jelgava, Latvia, pp. 19-23.

[2] Guidebook of reed business. "Cofreen. Reed for bioenergy and construction." [online] [29.03.2020]. Available at: https://ej.uz/ndf8.

[3] Reed construction. Reports from Turku University of Applied Sciences. Turku University of Applied Sciences. [online] [29.03.2020]. Available at: http://julkaisut.turkuamk.fi/isbn9789522160379.pdf

[4] Lizasoain J., Rincon M., Theuretzbacher F., Enguidanos R., Nielsen P.J., Potthast A., Zweckmair T., Gronauer A. and Bauer A. Biogas production from reed biomass. Biomass and Bioenergy 95, 2016, pp. 84-91.

[5] Vespere A., Popluga D. Assessment of reed potential for thermal energy production in Latvia. Proceedings of the 8th International Scientific Conference "Rural Development 2017", Nov 2324, 2017, Aleksandras Stulginskis University, Kaunas, Lithuania, pp. 485-489. 